\title{
Do imaginário coletivo em torno dos indígenas na região de Rio Negro-PR: um estudo dos relatórios de governo $(1853-1890)$.
}

\section{From the collective imaginary around the Indians within the Rio Negro-PR Region: a study of government reports (1853-1890).}

Soeli Regina Lima*

Resumo: O presente artigo procura estudar a concepção do indigena criada a partir de narrativas produzidas nos discursos governamentais. Delimitamos a região de Rio Negro- PR, no período de 1853 a 1890. Como fonte de pesquisa, nos pautamos nos relatórios do governo, no Catálogo Seletivo de Documentos referentes aos indígenas no Paraná Provincial (1853-1892), em pesquisas bibliográficas e na história oral. Constatou-se que a narrativa adotada pelos órgãos governamentais em relação aos indigenas nos primeiros contatos entre colonizadores e índios, do trabalho realizado nos aldeamentos, contribuiu para a formação do imaginário coletivo sobre o indígena na região de Rio Negro-PR.

Palavras-chave: imaginário coletivo, índios, narrativas.

\begin{abstract}
The present article aims to study the Indiginous conception created from narratives produced in government discourses. It was delimited the region of Rio Negro-PR, within the period 18531890. As a fountain of research, we based our studies in the government reports, in the Selective Catalogue of Documents in Provincial Paraná (1853-1892), in bibliographic researches and in the oral history. It was noticed that the narrative adopted by the governmental organs related to the Indiginous, in the first contacts between the colonizers and the Indiginous, from the works made in the communities, contributed for the construction of the collective imaginary about the Indiginous, within the Rio Negro-PR region.
\end{abstract}

Key-words: collective imaginary; Indians; narratives.

\section{Do imaginário coletivo}

A ocupação e formação da sociedade do planalto Norte catarinense e Sul paranaense deu-se com grandes disparidades, contradições e antagonismos culturais de grupos humanos, disputando o território com os indígenas do povo Xokleng para atender as necessidades de sobrevivência e "progresso" dos colonizadores. Nessas lutas o imaginário coletivo acerca da cultura indígena foi produzida.

Nesta análise pensamos imaginário "Em sentido mais especifico, é o conjunto de representações, crenças, desejos, sentimentos, através dos quais um indivíduo ou um grupo de

\footnotetext{
* Possui Mestrado em Geografia pela Universidade Federal do Paraná (2007), Especialização em História do Brasil e Graduação em História pela Faculdade Estadual de Filosofia Ciências e Letras de União Vitória. É membro da Academia de Letras do Vale do Iguaçu, Presidente da Academia de Letras do Brasil- Canoinhas. Atua como Docente da UnC- Universidade do Contestado.
} 
indivíduos vê a realidade e as si mesmo" (JAPIASSU; MARCONDES,1996, p.139), ou ainda, "significa o conjunto de imagens guardadas no inconsciente coletivo de uma sociedade ou de um grupo social; é o depósito de imagens de memória e imaginação” (SILVA, 2009, p.214).

O imaginário coletivo vai sendo construído a partir da forma como as pessoas compreendem e representam seu cotidiano em suas memórias. Assim sendo, "o estudo da memória coletiva se refere ao tempo como categoria organizadora do conhecimento" (VALENCIA,2005, p.99).

Podemos estudar o imaginário pela iconografia ou pelos discursos, que reproduzem figuras da memória de uma época, o que implica conhecer "todo o seu sistema social, a religião, as crenças, as relações de classe, as formas de comunicação etc, pois o imaginário perpassa todos esses elementos e só pode ser estudado com a observação da totalidade da estrutura social" (SILVA, 2009, p.214).

Sobre a forma como se constrói um objeto discursivo, Foucault (2002) aponta quatro observações e consequências: as condições para que apareça um objeto de discurso; as relações estabelecidas entre instituições, processos econômicos, sociais e judiciais; as distinções das relações primárias com o discurso das instituições técnicas, formas sociais, etc. e por último as relações discursivas não são internas ao discurso.

No caso de análise de discursos Foucault (2002) afirma que não é necessário remeter o discurso a longínqua presença das origens, mas sim, tratá-lo no jogo das instâncias a partir da qual são construídos.

Aceitarei os conjuntos que a história me propõe apenas para questioná-los imediatamente; para desfazê-los e saber se podemos recompô-los legitimamente; para saber se não é preciso reconstituir outros; para recolocá-los em um espaço mais geral que, dissipando sua aparente familiaridade, permita fazer sua teoria" (FOUCAULT, 2002, p.30).

Ou ainda,

A análise do campo discursivo é orientada de forma inteiramente diferente; trata-se de compreender o enunciado na estreiteza e singularidade de sua situação; de determinar as condições de sua existência, de fixar seus limites da forma mais justa, de estabelecer suas correlações com outros enunciados a que pode estar ligado, de mostrar que outras formas de enunciação exclui (FOUCAULT, 2002, p.31).

Para Foucault (2002, p. 36), "Os enunciados, diferentes em sua forma, dispersos no tempo, formam um conjunto quando se referem a um único e mesmo objeto". No caso da cultura indígena, romances, narrativas da imprensa, crônicas, relato de viajantes, relatórios de 
governos, história oral, documentários e memória familiar são os enunciados, que deram forma ao imaginário coletivo.

Pensando as permanências das representações no imaginário coletivo como decorrentes da memória familiar precisamos adentrar na esfera da memória coletiva e das suas formas de produção. A memória familiar possibilita a reconstrução de tempos históricos nem sempre registrados de forma escrita ou iconográfica.

Melhy (2002) ressalta que a memória pessoal é biológica e cultural, enquanto a grupal é essencialmente cultural e transcendente, ou seja:

A primeira só tem sentido nos exames individuais, das pessoas isoladamente. A segunda, em função dos mecanismos sociais, que explicam as atitudes individuais. Para a história oral, a memória individual só interessa na medida em que permite conhecimento do fenômeno social (MELHY, 2002, p. 52).

Já para Silva (2009, p. 276), seria a memória coletiva aquela "composta pelas lembranças vividas pelo indivíduo ou que lhe foram repassadas, mas que não lhe pertencem somente, e são entendidas como propriedade de uma comunidade, um grupo". Ela se desenvolve a partir de laços de convivência familiares e sociais. Esta recordação familiar é transformada pelas vicissitudes do tempo em que seus membros acrescentam, unificam, diferenciam.

Ainda no que se refere à memória coletiva, esta gira quase sempre em torno do cotidiano de um grupo, fundamentando a própria identidade dos mesmos ou de uma comunidade, se apegando a um fato como fundador, simplificando o restante do passado.

Em se tratando da memória individual, pode-se afirmar que ela é um ponto de vista sobre a coletiva.

Suas recordações pessoais são pessoais, somente à medida que ele se localizou num ponto em que foi possível ser atravessado por correntes de pensamento coletivo que formou uma configuração de maior complexidade para desvendar suas origens para a maioria das outras pessoas (ALBUQUERQUE JÚNIOR, 2007, p. 204).

As memórias individuais e coletivas são interdependentes e uma se explica pela outra. “A memória individual apenas serve para dar sentido às situações sociais, convém supor atenção prevalente à memória grupal, que, contudo, é sempre filtrada pelas narrativas pessoais" (MELHY, 2002, p.61).

Como categoria da memória Melhy (2002) afirma que a história oral tem compromisso com classes sociais, etnias, gênero e circunstâncias históricas. Independente da categoria de memória escolhida é fundamental que se leve em conta o lugar dos indivíduos ou grupos que 
projetam suas versões. Sem essa referência a análise social será incompleta, pois as memórias vão sendo produzidas como processo histórico vivido.

\section{Da produção do imaginário coletivo acerca dos indígenas}

Procuramos, neste trabalho, analisar representações sobre a cultura indígena, seja no que tange a memória individual ou coletiva, em suas diferentes temporalidades, pois são produções que se pautam no "não contato com estes sujeitos", por isso, seus discursos são fundados em enunciados de outros sujeitos, ou fontes e não da experiência. Há enunciados que se repetem ao longo das produções historiográficas. O que é então a cultura indígena? Será que não passa de um reagrupamento retrospectivo pelo qual as representações ao fato se iludem ao próprio passado? São formas de relatar os fatos que se instauraram definitivamente e se desenvolveram soberanamente através do tempo? Encobrem outras circunstâncias? E que espécie de laços as narrativas de governo e familiares sobre os índios contribuiu para os enunciados se formarem no imaginário coletivo?

De acordo com Japiassu (1996, p.61): “A cultura praticamente se identifica com o modo de vida de uma população determinada, vale dizer, com todo o conjunto de regras e comportamentos pelos quais as instituições adquirem um significado para os agentes sociais e através dos quais se encarnam em condutas mais ou menos codificadas" (JAPIASSU, 1996, p.61). A definição para cultura, criada no século XIX, por Edward Tylor, afirma:

cultura abrange todas as realizações materiais e os aspectos espirituais de um povo. Ou seja, em outras palavras, cultura é tudo aquilo produzido pela humanidade, seja no plano concreto ou no plano imaterial, desde artefatos e objetos até as ideias e crenças. Cultura é todo complexo de conhecimentos e toda habilidade humana empregada socialmente. Além disso, é também todo comportamento aprendido, de modo independente da questão biológica" (SILVA; SILVA, 2009, p.85).

Cabe ressaltar, que no universo cultural há regras que possibilitam aos indivíduos viver em sociedade. A cultura permite a adaptação dos sujeitos ao meio social e natural. E ainda, as culturas têm uma estrutura própria, mudam, são dinâmicas, alterando as relações sociais e de pertencimento dos integrantes que formam o grupo.

Gruzinski (1991) afirma que a ideia de cultura precisa ser repensada no tocante aos processos de mediação e mestiçagem; de maneira comum, a cultura é tratada enquanto singular ou pura, quando na verdade, o que se observa, pesquisa e problematiza, são processos híbridos. 
Nesse sentido, o próprio conceito de mestiçagem designa aquilo que nasce da mistura entre diferentes, seja num sentido de mesclas biológicas ou culturais.

Estratégias para a dominação dos povos indígenas foram adotadas no processo de dominação dos europeus no continente americano. A colonização portuguesa não diferiu, neste sentido, da ocupação espanhola ou inglesa, quanto a busca pelo aniquilamento da cultura indígena.

No viés da aculturação, os grupos (indígenas ou não) eram entendidos como sujeitos que passavam por um esvaziamento de suas culturas originais. E quando resistiam a esse esfacelamento, tal práxis era vista como um ato de extrema bravura e rebelião, mas que acabava reprimida pelo manto do poder colonial e, vencida, não restava nada além da submissão (OLIVEIRA, 2018, p.24).

A forma de conceber o indígena brasileiro, durante o processo de ocupação territorial europeia, esteve pautada em discursos da sua inferioridade e da necessidade de moldá-lo, modificando seus hábitos, inserindo-os nos moldes da cultura ocidental. Ele era percebido como obstáculo para os objetivos dos colonizadores.

Outros indígenas assimilavam essa nova forma de viver como garantia de sobrevivência contribuindo com o colonizador no extermínio de outras populações indígenas rivais. "Alguns se acercavam e aderiam, preferindo a aventura do convívio com os novos senhores, como flecheiros de suas guerras contra os índios arredios, do que a rotina da vida tribal, que perdera o viço e o brilho" (RIBEIRO, 1995, p.44). Cabe ressaltar, "Na documentação sobre conflitos de terra é possível constatar que, apesar do intenso processo de mestiçagem, os índios das antigas aldeias mantinham a vida comunitária e o sentimento de comunhão étnica que se manifestava sobretudo nas ações políticas para garantir os direitos que lhes haviam sido concedidos" (ALMEIDA, 2012, p.06).

Almeida (2012, p.02) discute a invisibilidade indígena na historiografia, enquanto sujeitos históricos no século XIX. "Vivos e atuantes nos sertões, vilas, aldeias e cidades do Brasil oitocentista, povos e indivíduos indígenas agiam e reagiam diferentemente às múltiplas formas de aplicação da política para eles traçada".

O contato entre europeus e indígenas foi permeado de leis que acabaram por contribuir na produção do imaginário coletivo acerca da cultura indígena. Partindo do pressuposto de que as narrativas governamentais refletem o pensamento de uma elite intelectual e são assimiladas 
por aqueles que as seguem, os relatórios de governo foram documentos de poder na produção do imaginário coletivo. A forma como estes relatórios forma produzidos, da sua organização, sistematização de informações, vocabulário empregado e fins que as narrativas visavam atingir nem sempre são perceptíveis, ou mesmo analisados pelos leitores. A grande maioria os recebe como discursos de pessoas ilustres que merecem ser respeitados, como verdades absolutas que acabam por serem repetidas. Desta forma expressões perpetuaram-se, estereótipos foram sendo elaborados e reelaborados acerca das culturas e dos fatos.

\title{
Da narrativa empregada na Lei do Diretório dos Índios de 1755.
}

A política Pombalina indígena foi marcada pela Lei do "Diretório dos Índios" ou "Diretório Pombalino" (1757) que regulamentava a vida indígena e as aldeias. Manteve o Diretório as linhas mestras do Regimento das Missões de 1686. No teor do seu texto podemos observar o pensamento em torno da cultura indígena, como "bárbaros", "incivilizados", desumanizando-os pelo não pertencimento a religião católica.

\begin{abstract}
Não se podendo negar, que os índios deste Estado se conservaram até agora na mesma barbaridade, como se vivessem nos incultos Sertões, em que nasceram, praticando os péssimos, e abomináveis costumes do Paganismo, não só privados do verdadeiro conhecimento dos adoráveis mistérios da nossa Sagrada Religião, mas até das mesmas conveniências Temporais, que só se podem conseguir pelos meios da civilidade, da Cultura, e do Comércio: E sendo evidente, que as paternais providências de Nosso Augusto Soberano, se dirigem unicamente a cristianizar, e civilizar estes até agora infelizes, e miseráveis Povos, para que saindo da ignorância, e rusticidade, a que se acham reduzidos, possam ser úteis a si, aos moradores, e ao Estado: Estes duos virtuosos, e importantes fins, que sempre foi a heróica empresa do incomparável zelo dos nossos Católicos, e Fidelíssimos Monarcas, serão o principal objeto da reflexão, e cuidado dos Diretores (LEI DO DIRETÓRIO DOS ÍNDIOS, 1755).
\end{abstract}

Pensava-se a educação ${ }^{i}$ das crianças indígenas como forma de moldar os futuros súditos do Rei, inserindo junto aos nativos a ideia do trabalho diferenciado entre homens e mulheres.

E como esta determinação é a base fundamental da Civilidade, que se pretende, haverá em todas as Povoações duas Escolas públicas, uma para os Meninos, na qual se lhes ensine a Doutrina Cristã, a ler, escrever, e contar na forma, que se pratica em todas as Escolas das Nações civilizadas; e outra para as Meninas, na qual, além de serem instruídas na Doutrina Cristã, se lhes ensinará a ler, escrever, fiar, fazer renda, costura, e todos os mais ministérios próprios daquele sexo (LEI DO DIRETÓRIO, 1755). 
A Lei do Diretório prescrevia como estratégia a inserção do indígena na sociedade civil. Acreditava-se que as honrarias de cargos dariam uma nova visão aos indígena. Através da sua autovalorização, prestigio junto as autoridades da Corte, usufruindo dos privilégios dos cargos eles perceberiam as vantagens da vida "civilizada" abandonado a antiga cultura. Vejamos o teor do texto:

E tendo consideração a que nas Povoações civis deve precisamente haver diversa graduação de Pessoas a proporção dos ministérios que exercitam, as quais pede a razão, que sejam tratadas com aquelas honras, que se devem aos seus empregos: Recomendo aos Diretores, que assim em público, como em particular, honrem, e estimem a todos aqueles Índios, que forem Juízes Ordinários, Vereadores, Principais, ou ocuparem outro qualquer posto honorífico; e também as suas famílias; dando-lhes assento na sua presença; e tratando-os com aquela distinção, que lhes for devida, conforme as suas respectivas graduações, empregos e cabedais; para que, vendo-se os ditos Índios estimados pública, e particularmente, cuidem em merecer com o seu bom procedimento as distintas honras, com que são tratados; separando-se daqueles vícios, e desterrando aquelas baixas imaginações, que insensivelmente os reduziram ao presente abatimento, e vileza (LEI DO DIRETÓRIO, 1755).

No que se refere a questão do trabalho, ele era fator cultural que interferia no projeto de desenvolvimento econômico português, diante da forma como o indígena concebia o trabalho. Acreditava-se que inserindo os indígenas no sistema produtivo seriam solucionados os problemas de "pobreza" outrora contatados nas aldeias.

Em primeiro lugar cuidarão muito os Diretores em lhes persuadir o quanto lhes será útil o honrado exercício de cultivarem as suas terras; porque por este interessante trabalho não só terão os meios competentes para sustentarem com abundância as suas casas, e famílias; mas vendendo os gêneros, que adquirirem pelo meio da cultura, se aumentarão neles os cabedais à proporção da lavoura, e plantações, que fizerem. E para que estas persuasões cheguem a produzir o efeito, que se deseja, lhes farão compreender os Diretores, que a sua negligência, e o seu descuido, tem sido a causa do abatimento, e pobreza, a que se acham reduzidos; não omitindo finalmente diligência alguma de introduzir neles aquela honesta, e louvável ambição, que desterrando das Repúblicas o pernicioso vício da ociosidade, as constitui populosas, respeitadas e opulentas (LEI DO DIRETÓRIO, 1755).

No que concerne ao controle da produtividade nos aldeamentos indígenas, observamos a prática da elaboração de relatórios anuais. Este controle acontecia para além dos relatórios, nas aldeias havia a punição e o reconhecimentos quanto a produção como forma de incentivar ao trabalho, acreditando-se que desta forma estariam mudando a índole indígena.

Para o Governador do Estado, sendo informado daqueles Índios, que entregues ao abominável vício da ociosidade faltarem à importantíssima obrigação da Cultura das suas terras, possa dar as providências necessárias para remediar tão sensíveis danos; 
serão obrigados os Diretores a remeter todos os anos uma lista das Roças, que se fizerem, declarando nela os gêneros, que se plantaram, pelas suas qualidades; e os que se receberam; e também os nomes assim dos Lavradores, que cultivaram os ditos gêneros, como dos que não trabalharam; explicando as causas, e os motivos, que tiveram para faltarem a tão precisa, e interessante obrigação; para que à vista das referidas causas possa o mesmo Governador louvar em uns o trabalho, e a aplicação; e castigar em outros a ociosidade, e a negligência (LEI DO DIRETÓRIO, 1755).

Cabe ressaltar outra estratégia de inserção do indígena na cultura dos colonizadores através de uniões matrimonias entre brancos e indígenas. Para tal, a legislação prescrevia inculcar na sociedade uma imagem de não inferioridade indígena, incentivando assim, as uniões. Ao mesmo tempo indígenas, que desenvolvessem determinadas funções, ocupando postos de trabalho, poderiam usufruir do mesmo tratamento aplicado aos "brancos" com honrarias e privilégios.

Para facilitar os ditos matrimônios, empregarão os Diretores toda a eficácia do seu zelo em persuadir a todas as Pessoas Brancas, que assistirem nas suas Povoações, que os Índios tanto não são de inferior qualidade a respeito delas, que dignando-se Sua Majestade de os habilitar para todas aquelas honras competentes às graduações dos seus postos, consequientemente ficam logrando os mesmos privilégios as Pessoas que casarem com os ditos índios; desterrando-se por este modo as prejudicialíssimas imaginações dos Moradores deste Estado, que sempre reputaram por infâmia semelhantes matrimônios (LEI DO DIRETÓRIO, 1755).

Como vemos, por meio do contato intercultural nas relações de trabalho, da educação e de uniões matrimonias, dentre outros, de tratamento aplicado ao indígena brasileiro na política indigenista Pombalina. Avançado no tempo ${ }^{\text {iiiiii }}$, para o século XIX, mais especificamente na Província do Paraná (1853-1889), vamos observar nos relatórios e correspondências de governo as narrativas empregadas em relação a cultura indígena.

\section{Das narrativas de governo na Província do Paraná sobre os indígenas (1853-1890).}

O atual estado do Paraná em seus primórdios pertenceu a Província de São Paulo, sendo elevado à categoria de Província no ano de 1853. No território paranaense foram contabilizados 10 aldeamentos entre os anos de 1810 a 1878 e outros 3 mantiveram-se ativos durante o período republicano (1920).

A partir de 1730, foi determinada pela Província de São Paulo a abertura de uma via de comunicação com Viamão pertencente a Capitania de São Pedro do Rio Grande do Sul, visando alcançar a feira de Sorocaba, em São Paulo, surgindo desta forma a Estrada da Mata ${ }^{\text {iv }}$. O 
município de Rio Negro- PR teve suas origens ao redor de um posto de Registro Fiscal, na região que era conhecida como Sertão da Mata. No ano de 1826, foi erguida a Capela da Mata do Caminho do Sul, em 1829 chegaram os primeiros imigrantes alemães, em 1839 o núcleo urbano foi elevado à categoria de Freguesia e em 1870 a vila passou a município. A região era ocupada pelos Xokleng, denominados de botocudos ${ }^{\mathrm{v}}$. Alguns aspectos de ordem cultural, dos botocudos, foram registrados no Catálogo Seletivo de Documentos referentes aos indígenas no Paraná provincial (1853-1870):

\begin{abstract}
Indígenas de várias etnias que usavam o botoque ou tembetá, adorno sub-labial inserido entre o lábio inferior e o queixo, dando uma aparência protuberante à face. Na província do Paraná eram designados de Botocudos os índios Xokleng ou Laklaño (autodenominação que significa gente do sol ou gente ligeira), da família lingüística Jê, no litoral e centro-sul do Paraná, além do nordeste de Santa Catarina, os Xetá, da família Tupi-Guarani e, ainda, mais esporadicamente, alguns Guarani que usavam o tembetá. Em outras províncias brasileiras houve grande número de etnias indígenas denominadas Botocudos devido ao uso deste adorno, que podia ser confeccionado em diferentes materiais, como resina de plantas, osso, pedra e madeira. Somente com uma análise de detalhe e contextualizada de cada documento descrito no presente catálogo, pode-se identificar o grupo indígena que está sendo referenciado (CATÁLOGO, 2007, p.16).
\end{abstract}

Veremos, na sequência, no decorrer da análise documental, a percepção do governo e moradores locais, referente a certos aspectos culturais dos Xokleng.

Era comum o uso da expressão "correria dos índios" para designar a presença indígena na região e como forma de contato usavam doar "brindes" (objetos do interesse indígena). Esta prática foi motivo de preocupação quanto ao tipo de objetos a serem doados.

[...] prohibi o uso de se dar aos índios errantes, instrumentos tão perigosos e fataes, permittindo apenas brinda-los com mimos inocentes e inoffensivos à desejada segurança individual, sempre arriscada ante indivíduos taes. E na verdade, comprehendo que vantagem se encontra na dadiva de machados, fouces, enchadas, etc., aos indígenas aldeados e já embuídos de alguma civilização, não só para os habilitar à lavoura, como para defesa do aldeamento, era caso extremo perigoso; mas aos que não se acham n'aquellas circumstancias, qualifico de temeridade fornecer taes dadivas (RELATÓRIO, 1860, p.54).

Outra justificativa para o fim do uso de brindes aparece no Relatório de 1862:

É preciso acabar com essa rotina estéril de brindes aos selvagens que os nelles vêm um engano e os suspeitam, ou um donativo sem valor, porque desconheciam o seu custo. $\mathrm{O}$ brinde quando dado ao selvagem em reconhecimento de alguma boa acção praticada, ou em remuneração de seo trabalho serve quando menos para ensinar-lhe, que o trabalho tem um valor; torna-se uma lição prática do- do ut facias. Brindar porem aos que fogem dos aldeamentos e preferem uma vida errante dos bosques é acoroçar as correrias e depredações (RELATÓRIO, 1862, p.80).

Verificamos ainda, a estratégia de implantação de colônias militares e aldeamentos na perspectiva de inserir o indígena no modelo capitalista de produção: 
Tirava-se partido da tendência natural do índio para o aparato da vida militar, e facilmente embuia-se-lhe amor ao trabalho e hábitos de subordinação pelo exemplo da disciplina dos soldados colonos. [..] O selvagem não se leva somente pela brandura: o medo e o reconhecimento e recursos do homem civilizado podem fazer talvez mais em um dia que brindes em um anno (RELATÓRIO, 1862, p.80).

Dito de outra forma: “Qualquer que sejam os encantos da civilização e do trabalho, não podem eles oferecer attactivos ao homem selvagem a efeito à completa ociosidade, por índole e hábitos que dificilmente poderão ser combatidos" (RELATÓRIO, 1878, p.57).

Sobre essa questão, Souza (2015) faz uma análise da atuação do cacique Kaingang Vitorino Condá em defesa da posse de terras, a partir do encontro político com o Conde de Caxias no ano de 1845 até sua morte em 1870. As populações indígenas do planalto Meridional, através de suas lideranças, que atuavam como interlocutores e, muitas vezes, engajavam-se em conversações e acordos com presidentes de Província, estabeleceram alianças, tentando assim manter a posse de terras. Em alguns casos contribuíram para a destruição de tribos rivais como os Xokleng, auxiliando a política indigenista de limpeza da região para ocupação colonizadora.

A busca por "civilizar" os indígenas era recorrente. Vejamos algumas expressões da época:

Habitando os aldeamentos, elles ali vivem como se morassem nas tendas de suas tribos, entregues a uma perigosa ociosidade; alheios completamente a nossa lingoa, com exceção de um ou outro, e ignorantes dos veres da religião, não obstante os esforços ensaiados pelos virtuosos missionários capuchinhos (RELATÓRIO, 1867, p.65).

Na questão do vestuário indígena, podemos identificar a concepção dos representantes do governo ao descreverem a passagem indígena pela capital da Província:

Completamente ignorantes, apresentam-se quase todos nús, e nenhuma importância ligam a roupa que se lhes fornece; preferem antes um rosário de missangas para adornarem o pescoço. Despresando os affagos da gente civilizada, elles procuram afastar-se dos povoados, tão depressa fazem acquisição dos brindes, que desejam obter, para satisfação da cubiça, que lhes é natural (RELATÓRIO, 1867, p.65).

Sobre o papel da catequese, ela era concebida como processo lento e com frutos a ser colhido através das crianças indígenas que estavam neste processo.

A experiência vae demonstrando cada vez mais que não se póde colher resultados immediatos dos esforços empregados para chamar à vida social e aos hábitos de trabalho, o selvagem brasileiro. A índole errante e independente do índio já adulto, tarde ou nunca se modificará; esforços incessantes e pacientes dos catechistas podem abrandar-lhes os mãos instinctos e isto já é uma importante conquista que a educação das crianças indígenas nos aldeamentos completará (RELATÓRIO, 1877, p. 106). 
A desterritorialização dos povos indígenas era uma necessidade do governo provincial. No caso dos índios Xokleng, na região de Rio Negro, eles estavam constantemente presentes nas correspondências de governo.

O contato com indígenas foi uma preocupação do administrador do Registro de Rio Negro, Firmino dos Santos Pacheco Lima, quando em 30/10/1858 comunicou que os tropeiros, Frederico Martins de Araújo e Generoso Martins de Araújo, informaram-lhe que índios haviam atacado o lugar denominado Saltinho, distante três léguas da Freguesia de Rio Negro (PR). (CATÁLAGO, 2007, p. 96). Lembrando a importância de Rio Negro, para a Província no que concerne a arrecadação de impostos. Situado na passagem da Estrada da Mata, o local merecia atenção na questão de segurança para os transeuntes. Os impostos cobrados eram taxados sobre animais, que era a principal receita, sobre a saída e entrada de escravos, do dizimo de exportação, de 3\% sobre gêneros destinados ao consumo e alguns outros de menor renda.

No ano de 1868 há registros de confronto ${ }^{\mathrm{vi}}$ com os indígenas na Freguesia de Rio Negro, onde foram mortos seis indivíduos.

Na noite de 13 para 14 no logar denominado -Passo Ruim - da estrada da Matta, 7 leguas distante daquella freguezia, Francisco Carvalho, Benedicto José Fernandes, José Mariano dos Santos, João Manoel Ribeiro e os menores João e Generoso, estando de pouso com a tropa em que conduziram alguns gêneros para o Lageadinho da província de Santa Catharina, foram assaltados e assassinados pelos índios selvagens. O subdelegado que foi ao logar para fazer o corpo de delicto e tomar as convenientes providencias, communicou-me que os cadaveres já em estado de putrefacção adiantada e completamente nús, excepto o de um dos menores, tinham sobre si 13 cacetes com quatro quinas e 7 palmos de comprimento, que haviam servido para espagar as cabeças das infelizes victimas. Os indícios e signaes encontrados attestavam ser considerável o numero de aggressores. Estes, derramando e espalhando pelo solo os gêneros, carreram os saccos, fazendas, todo o metal que encontraram e as esteiras das cangalhas (RELATÓRIO, 1868, p.05).

Avançando no tempo observamos que em 29 de maio de 1873 foi solicitada uma escolta de 25 a 30 pessoas para afugentar os indígenas, diante da reclamação do moradores da Estrada da Mata (CATÁlOGO, 2009, p.71). O Coronel David dos Santos Pacheco, Comandante Superior da Guarda Nacional da Lapa-PR e de Rio Negro-PR, no ano de 1874, informou que já havia ordenado, ao capitão interino do $5^{\circ}$ Esquadrão de Rio Negro, para que cedesse algumas praças ao delegado de polícia, a fim de prevenir um possível ataque indígena

Diante da presença indígena foi implantado o aldeamento São Thomás de Papanduva. Em julho de 1875 o Ministro da Agricultura, Comércio e Obras Públicas autorizou a demarcação das terras escolhida pelo sertanista Joaquim Francisco Lopes para a fundação do 
citado aldeamento na vila de Rio Negro (CATÁLOGO, 2009, p.172). O aldeamento funcionou até o ano de 1877.

Passados dois meses da extinção do aldeamento, em março de 1878, a presença dos índios botocudos foi registrado pelos moradores, com a expressão "estão rodando" o antigo aldeamento fazendo barulhos com paus, matando animais e invadindo roças. Novamente é solicitado brindes para poder "amansá-los" (CATÁLAGO, 2008, p.232).

No relatório do presidente da Província foram citados confrontos dos índios com os moradores locais de Papanduva, no mês de fevereiro de 1879. Vejamos o teor do relato:

No lugar denominado Papanduva, districto do Rio Negro, em meados deste mez, estando Cezario Antonio Ribeiro em companhia de seu sogro Joaquim Torquato de Assis, partindo um pinheiro, distante 50 braças $^{\text {vii }}$ da casa deste, forão assaltados pelos índios botocudos, recebendo Ribeiro duas flechadas, atravessando a primeira a coxa direita, e a segunda cravando-se no hombro direito do mesmo lado. O subdelegado de policia, tendo conhecimento deste facto lamentável, dirigiu-se para ali e procedeu o auto de corpo de delicto no offendido (RELATÓRIO, 1879, p.IX-X).

As correspondências citando a presença indígena sucederam-se. O problema com os indígenas conduziu Martin Mader, subdelegado de polícia de Rio Negro, a pedir demissão do cargo em 30 de outubro de 1880, lembrando de que não havia suplente juramentado para assumir sua função. $\mathrm{O}$ fato se deu após informar que os contínuos ataques dos indígenas, no quarteirão do Campo da Estiva, causaram grandes prejuízos para os habitantes com a perda dos animais. Comunicou que fez nova expedição àquele quarteirão, passando, inclusive, pelo extinto aldeamento de São Thomaz de Papanduva, onde alguns indígenas ainda estavam alojados (CATÁLAGO, 2009, p.356).

Os confrontos persistiram. Em agosto de 1880 o subdelegado de polícia de Rio Negro informou sobre o ataque dos botocudos à população e aos animais nas localidades de Papanduva, Estiva e Saltinho. Ele acreditava que o restabelecimento do aldeamento de Papanduva seria uma boa solução para contê-los (CATÁLAGO, 2009, p.351).

Os anos foram sucedendo-se e o convívio entre moradores e indígenas continuou conflituoso. Em 1886, oito anos após a extinção do aldeamento, foi registrada a necessidade de seu reativamento:

Em officio de 16 de setembro, esta repartição solicitou a V. Ex. a restauração do antigo aldeamento de $\mathrm{S}$. Thomaz de Papanduva como medida de prevenção para tranquilidade dos habitantes daquelas immediações, e também para segurança dos viajantes; precedendo ao aldeamento medidas profícuas de catechese (RELATÓRIO, 1887, p. 54). 
As correspondências revelam que os indígenas resistiram aos conflitos, por meio de diferentes formas de "resistência". A luta pela posse de suas terras e o direito a preservação de sua cultura foi uma marca dos Xokleng na região de Rio Negro-PR.

\section{Da produção do imaginário coletivo acerca dos indígenas através da história oral.}

Para adentrarmos na análise das permanências no imaginário coletivo acerca dos indígenas nos pautamos em duas entrevistas semiestruturadas de história oral. Selecionamos a entrevista de uma descendente de imigrantes poloneses da região de Rio Negro- PR e outra de descendente de colonizadores portugueses que colonizaram a região de Canoinhas-SC, nos seus primórdios pertencentes ao município de Rio Negro- PR.

Maria Kovalski Procheira, atualmente residente em Três Barras-SC, descendente de poloneses, relata a experiência de seus antepassados com os índios na formação das colônias de imigrantes na região de Rio Negro-PR. Nascida em 17/05/1929 morou nas localidades de Craveiro, Colônia Beker e Iracema (Itaiópolis-SC), pertencente ao município de Rio Negro-PR até sua emancipação política.

De sua memória familiar ela descreve que o avô e vizinhos, imigrantes poloneses, juntaram dinheiro e compraram o terreno na região. Quando estavam iniciando a colônia, para evitar o confronto com os indígenas, tinham por hábito trabalharem sempre coletivamente, evitando o isolamento nas matas. Um episódio de confronto armado com indígenas, vivenciado pelo avô, foi sendo transmitido de geração em geração. Vejamos em suas palavras:

Daí um disse: Agora imo pro vizinho derrubar o mato, mas vamos se juntar todos porque tavam com medo. Os bugres tavam avançando muito. Daí eles foram, cortaram, roçaram e foram no almoço. Então esses bugres, esses índios, tudo, foram nesse mato e se cobriram com folhas, desses matos, que eles cortaram, pra eles não ver eles. Quando voltaram derrubar matos, eles levantaram e avançaram. Era com machado, era com foice cortaram. E daí não dá pra contar [para emocionada] quando esses caixão quando a mulherada tavam juntando os pedaços, já estou gelada; esses pedaços de pé, pedaço de mão, pedaço de cabeça, juntando nos caixão. Mas isso muitos anos, isso eu não vi. (PROCHEIRA, 2014).

Ao descrever o convívio com indígenas nas proximidades das residências, ela relata:

Pra pai ir pra vila, juntava os vizinhos. Então minha mãe, já tinha casa, mas não é parede assim com tábua, era com rachão do mato. Já se guardava ligeiro de dia, tinha que se esconder. Quando viu, veio já e encheu de coisa nas portas, de galho, de tudo. Então mãe, não podia abrir. Depois, de dia, não podia sair pra fora. Daí, deu trabalho pra mãe. Nóis tava chorando, queria ir pra fora, não podia sair. Mais isso tava triste! E não deu pra mexer com eles, porque eles subiram na árvore e tavam dando risada, quando isso 
já estava clareando o dia. E a cachorrada tavam avançando neles. Eles tinham muito medo de cachorro (PROCHEIRA, 2014).

O fato dos indígenas passarem horas próximo as casas, apenas observando e assustando os colonos revela a concepção indígena de pertencimento no território ocupado, da necessidade dos ditos "homens brancos" saírem do local e não da intenção de cometer atrocidades. Não se trata de amenizar as mortes praticadas por indígenas e "brancos", mas sim, de revelar universos culturais distintos em jogo na disputa pela posse da terra.

Interessante observar o imaginário coletivo dos imigrantes sobre os índios que difere das narrativas de governo. Na visão dos colonos imigrantes, eles estavam ocupando o território indígena. O sentimento de pertencimento do território, por parte dos indígenas, ficou evidente no depoimento a seguir:

mais isso mataram gente, gente, gente... Porque eles falaram que terra do Brasil é deles. Mas isso tem lugar que eu passo as vezes e ainda to escuitando grito: - terreno é nosso. Ainda tem lugar, porque mundo é grande, não tem fim. Pouco se lembro que pai disse: - Isso vem ainda eles. No final eles que vão mostrar a guerra (PROCHEIRA,2014).

Já a entrevistada Izabel Mattos Mota, nascida em 10/07/1922, filha de José Tomas de Mattos e Ana Maria de Mattos é descendente de família colonizadora ${ }^{\text {viii }}$ da região. Seu esposo era descendente da família Mota. Cabe ressaltar o nome original da Estrada da Mata era Estrada do Mota, alusivo ao seu executor, o curitibano Manoel Rodrigues da Mota, que partiu de Curitiba, cruzou os rios Iguaçu e Negro, abrindo uma picada até o Campo de Lages.

Nascida na localidade de Pinheiros, próximo a Serra das Mortes, mas registrada na Localidade de Taunay (Canoinhas-SC). Dona Izabel relata sobre a presença indígena na região. "Serra das Mortes, perto de Pinheiro, é por causa da morte de uma família que os índios mataram. E essa família eram primos da minha falecida mãe. O maior da família era irmão da minha avó, da mãe da minha mãe” (MOTA, 2017).

Podemos situar a história oral com o relato de viajantes sobre a presença indígena na região. O então presidente da Província do Paraná, Visconde de Taunay, através do relato ${ }^{\mathrm{ix}}$ de sua viagem fluvial realizada no mês de março de 1886, deixa as suas impressões da região. Ele viajou os 330 quilômetros navegáveis a partir de Porto Amazonas (Curitiba-PR). Foi nesta viagem, quando de passagem, pela região que ele denominou a localidade com o seu nome de Taunay.

Após o registro da passagem pela barra do Rio Claro e do Paciência, o vapor parou no lugar chamado Chapeo do Sol, para abastecimento de lenha; neste local o governador desembarcou e foi recebido por moradores de duas casinhas próximas que lhes ofereceram 
galinhas, ovos, leite, melancias, recebendo dinheiro, doces e biscoito. Sobre essa pequena comunidade foi feita referência as dificuldades ali enfrentadas com a presença indígena:

Essa pobre gente para alli, num recanto da zona de vagabundagem e correrias de indômitos bugres botocudos, a cujos assaltos estão sujeitos. O pae de uma rapariguinha, e o marido de uma mulher, que ainda lá morão, havião sido mortos no anno passado e flexadas, quando trabalhavão nas roças; e suas sepulturas, amparadas por grandes cruzes feitas de fresco, dão melancolica solemnidade à solitária barranca (TAUNAY, 1886, p. XI).

Sobre o contato do Senhor Valões, considerado pioneiro na colonização do município de Irineópolis-SC, com os indígenas, podemos observar:

Um quarto de légua adiante habita laborioso e enérgico brasileiro, chamado Vallões, que parece prosperar bastante. Trabalha armado e sempre prompto para qualquer investida, servindo sem duvida, e muito a sua reputação de intrepidez, de aute mural a qualquer tentativa de agressão por parte d’esses índios, cujos hábitos de trahição só são excedidos pelo receio de serem repellidos, e acossados em regra (TAUNAY, 1886, p. XI-XII).

Ao passar pelo rio Timbó, a presença indígena é destacada: “Approximava-se a boca do majestosos Timbó e appareceo entre nós a idéa, logo aceita, de faze-lo sulcar pelo vapor, pois sua corrente até hoje fôra virgem de qualquer embarcação, até canoa, pelo terror que inspirão as margens infestadas de indios bravios" (TAUNAY, 1886, p. XII). Como forma de proteção foram lançados foguetes, disparadas armas, soltados prolongados apitos, espantando, assim, a presença indígena.

Retornando a memória familiar, no que concerne a estratégia de casamento com indígenas para garantir a ocupação territorial, esta foi uma realidade da família Mattos. Dona Izabel narra:

E do meu pai: o avô dele de Portugal e a avó dele índia, dessa região de Taunay aí. Ele ganhou terras do governo, daí como não podiam entrar por ali. Eles vieram pelo rio que era navegável, o Rio Negro, de canoas, mas eles já vieram de vapor pra ir para as serras. Depois não podiam entrar por causa dos índios. Não tinha estrada de ferro, nada, ainda, quando meus bisavós vieram. Meu bisavô porque minha bisavó era índia. Teve que agradar os índios, daí ficou com uma, teve filhos tudo com aquela uma. Eu tenho sangue de índios (MOTA, 2017).

Darcy Ribeiro define a uniões entre índios e brancos com a expressão de cunhadismo.

A instituição social que possibilitou a formação do povo brasileiro foi o cunhadismo, velho uso indígena de incorporar estranhos à sua comunidade. Consistia em lhes dar uma moça índia como esposa. Assim que ele a assumisse, estabelecia, automaticamente, mil laços que o aparentavam com todos os membros do grupo" (RIBEIRO, 1995, p. 81) 
Do resultado destas uniões Darcy Ribeiro conclui:

Assim é que, por via do cunhadismo, levado a extremo, se criou um gênero humano novo, que não era, nem se reconhecia e nem era visto como tal pelos índios, pelos europeus e pelos negros. Esse gênero de gente alcançou uma eficiência inexcedível, a seu pesar, como agentes da civilização. Falavam sua própria língua, tinham sua própria visão do mundo, dominavam uma alta tecnologia de adaptação à floresta tropical. Tudo isso aurido do seu convívio compulsório com os índios de matriz tupi” (RIBEIRO,1995, p. 109).

Dona Izabel, no que se refere a forma de conceber o trabalho, como fator cultural indígena, revela a permanência no imaginário coletivo dos primeiros discursos de documentos oficiais na memória familiar:

Índio é meio parado, português também não é muito do trabalho, é mais da oportunidade né. Índio com português já viu. Daí a minha avó que era estrangeira era mais ativa. [...] Ela já era mais culta, tinha cultura, vieram de Palmeira. Ela que trouxe a moda para as filhas dela, tudo, aqueles corpete, aquelas coisas (MOTA, 2017).

Neste mesmo depoimento, outro ponto a destacar, está na concepção do trabalho. Constatamos a ideia da cultura estrangeira sobrepondo-se com seus valores morais e éticos sobre a do indígena e do caboclo (mestiço de branco com índio).

\section{Considerações finais:}

Constatamos que a desumanização do indígena, a inferiorização do sujeito em comparação com a sociedade ocidental dominante acabou por legitimar a implementação de leis e as narrativas do governo imperial. A concepção inferiorizada da cultura indígena foi usada como justificativa na violência praticada contra os mesmos, sendo o princípio para a dizimação em massa de tribos indígenas. Nas palavras de Darcy Ribeiro:

Conforme se vê, a população original do Brasil foi drasticamente reduzida por um genocídio de projeções espantosas, que se deu através da guerra de extermínio, do desgaste no trabalho escravo e da virulência das novas enfermidades que os achacaram. A ele se seguiu um etnocídio igualmente dizimador, que atuou através da esmoralização pela catequese; da pressão dos fazendeiros que iam se apropriando de suas terras; do fracasso de suas próprias tentativas de encontrar um lugar e um papel no mundo dos "brancos". Ao genocídio e ao etnocídio se somam guerras de extermínio, autorizadas pela Coroa contra índios considerados hostis, como os do vale do rio Doce e do Itajaí. Desalojaram e destruíram grande número deles (RIBEIRO, 1995, p.144-145).

Esses grupos indígenas circulavam de uma região à outra, assim, não houve o aniquilamento, nem mesmo, sofreram uma limpeza étnica. Eles passaram pelo processo de mestiçagem e migração para outros espaços que eram também tradicionais. As fontes orais contemporâneas 
evidenciam um distanciamento, do tipo: "antes eles viviam por aqui ou ali, agora não mais..." Desta forma conclui-se que seguiram integrando-se a sociedade, resistiram em reservas e em outras formas de sobrevivência.

Observamos no decorrer da análise das narrativas de documentos e correspondências de governo que a concepção do colonizador acerca da cultura indígena produzida no século XVIII e XIX, pela elite político administrativa, foi transposta para o cotidiano da população brasileira. $\mathrm{Na}$ atualidade, essas concepções vem sendo desconstruídas. Na investigação histórica, os indígenas vão, de forma gradativa, passando da invisibilidade construída no século XIX para o protagonismo conquistado nos séculos XX e XXI por movimentos intelectuais e políticos, onde eles próprios têm tido intensa participação (ALMEIDA, 2012).

A memória familiar contribuiu para as produção do imaginário coletivo. Os conceitos foram derivando-se em novos conceitos carregados do mesmo sentido. A unidade e persistência das informações sobre os indígenas demonstram os princípios de individualização do discurso.

Podemos demarcar o momento primeiro de emergência do imaginário coletivo nas narrativas documentais. Estas revelam a forma de conceber um povo e seus costumes que perpetuou-se nos séculos subsequentes. $\quad \mathrm{Na}$ região de Rio Negro-PR, a colonização enfrentou universos culturais distintos. O aldeamento São Thomas de Papanduva teve pouco tempo de existência. Num mesmo território sociedades, com diferenças culturais, precisaram adaptar ao convívio, onde as fontes, colocadas em seu contexto de produção, permitiram compreender o lugar dos seus atores, seus interesses e tensões, cujas narrativas, revelaram os indígenas enquanto interlocutores nesse processo de contato a partir de mediações culturais.

Cabe investigar o imaginário coletivo dos descendentes dos indígenas sobre esta fase da história. Como a memória coletiva familiar descreve o passado histórico vivido. Mas isso é assunto para pesquisas futuras.

\section{Referências bibliográficas}

ALBUQUERQUE JÚNIOR, Durval Muniz de. História a arte de inventar o passado: ensaios de teoria da História. Bauru- SP: EDUSC, 2007.

ALMEIDA, Maria Regina Celestino de. Os índios na História do Brasil. Rio de Janeiro: Editora FGV, 2010.

Os índios na História do Brasil no século XIX: da invisibilidade ao protagonismo. In: Revista História Hoje, v. 1, no 2, 2012, p. 21-39. Disponível:<file:///C:/Users/ACER/Downloads/39-72-1-SM.pdf>.

Acessado: 
13/09/2018.BÁEZ, Fernando. A história da destruição cultural da América Latina: da conquista à globalização. Trad. Léo Schlafman. Rio de Janeiro: Nova Fronteira, 2010.

BROWN, Dee. Enterraram meu coração na curva do rio: a dramática história dos índios norteamericanos. Trad. Geraldo Galvão Ferraz e Lola Xavier. Porto Alegre-RS: L\&PM, 2010.

CATÁLAGO, seletivo de documentos referentes aos indígenas no Paraná provincial: 1853 1870. Curitiba, 2007. (Coleção Pontos de Acesso, V.03). Disponível: Arquivo Público do Paraná < http://www.arquivopublico.pr.gov.br/arquivos/File/pdf/catalogo_indigena_L.pdf>

CATÁLAGO, seletivo de documentos referentes aos indígenas no Paraná provincial: 1871 1892. Curitiba, 2009. (Coleção Pontos de Acesso, V.04). Disponível: Arquivo Público do Paraná<http://www.arquivopublico.pr.gov.br/arquivos/File/pdf/catalogoindigena_1871_1892. pdf $>$.

FOUCAULT, Michel. A arqueologia do saber. Trad. Luiz Felipe Baeta Neves. 6 ed. Rio de Janeiro: Forense Universitária,2002.

GOULARTI FILHO, Alcides. A Estrada da Mata e a integração regional pelo Brasil Meridional. In: Textos de Economia, Florianópolis, v.15, n.2, p.111-138, jul./dez.2012. Disponível:<https://periodicos.ufsc.br/index.php/economia/article/view/21758085.2012v15n2 p111>. Acessado em: 12/12/2017.

RUZINSKI, S. La colonización de lo imaginario: sociedades indígenas y occidentalización en el México español - siglos XVI-XVIII. Mexico, DF: Fondo de Cultura Económica, 1991.

JAPIASSU, H.; MARCONDES, D. Dicionário Básico de Filosofia. Rio de Janeiro: Zehar,1996.

LEI DO DIRETÓRIO DOS ÍNDIOS. Transcrição da lei de 1755. Disponível: <http://www.nacaomestica.org/diretorio_dos_indios.htm>. Acessado em 20/01/2018.

LIVRO DE ATAS -1898 a 1903. Lista de eleitores qualificados do município de Rio Negro 04/12/1898. Acervo da Câmara Municipal de Rio Negro-PR.

MELHY, José Carlos Sebe Bom. Manual de História oral. 4 ed. São Paulo: Edições Loyola, 2002.

MOTA, Izabel Mattos. Entrevista concedida à Soeli Regina Lima. Canoinhas, 2017. Disponível: < https://www.ecosdocontestado.com/memorias> Acessado em: 24/02/2018.

MOTA, Lúcio Tadeu. Passo Ruim 1868: as estratégias dos Xokleng nas fronteiras de seus territórios do alto rio Itajaí. IN: Revista Brasileira de História. 2017, vol.37, n.75, pp.169193.Disponível: $<$ http://www.scielo.br/scielo.php?pid=S010201882017005004103\&script=sci _abstract\&tlng=pt $>$. Acessado em: 02/02/2018.

OLIVEIRA, J. C. de. (Des)caminhos das Jornadas Meridionais: representações indígenas e estratégias de mediação cultural no contexto indigenista em meados do século XIX. 2018, $213 f$. Dissertação (Mestrado em História), Universidade Estadual de Ponta Grossa, Ponta Grossa, 2018. Disponível: <http://tede2.uepg.br/jspui/handle/prefix/2588>. Acessado em: 10/09/2018. 
PROCHEIRA, Maria Kovalski. Entrevista concedida à Soeli Regina Lima. Três Barras-SC, 2014 Disponível: < https://www.ecosdocontestado.com/memorias> Acessado em: 24/02/2018.

RELATÓRIO do presidente da Província do Paraná Adolpho Lamenha Lins apresentado a Assembleia Legislativa em 13 de fevereiro de 1877. Disponível:< http://www.arquivopublico.pr.gov.br/arquivos/File/pdf/rel_1877_a_p.pdf> Acessado em: $11 / 11 / 2017$.

RELATÓRIO do presidente da Província do Paraná Bacharel José Feliciano Horta de Araujo apresentado a Assembleia Legislativa em 15 de fevereiro de 1868. Disponível:< http://www.arquivopublico.pr.gov.br/arquivos/File/pdf/rel_1868_a_p.pdf> Acessado em: $11 / 11 / 2017$.

RELATÓRIO do presidente da Província do Paraná Bacharel Manuel Pinto de Souza Dantas apresentado a Assembleia Legislativa em 04 de junho de 1879. Disponível:< http://www.arquivopublico.pr.gov.br/arquivos/File/pdf/rel_1879_a_p.pdf>Acessadoem:11/11/ 2017.

RELATÓRIO do presidente da Província do Paraná Dr. Joaquim Bento de Oliveira Junior apresentado na transmissão da administração da Província ao $1^{o}$ Vice-Presidente Jesuino Marcondes de Oliveira Sá em 07 de fevereiro de 1878. Disponível:< http://www.arquivopublico.pr.gov.br/arquivos/File/pdf/rel_1878_b_p.pdf> Acessado em: $11 / 11 / 2017$.

RELATORIO do presidente da Província do Paraná Dr. Joaquim d Almeida Farinha Sobrinho apresentado a Assembleia Legislativa em 17 de fevereiro de 1887. Disponível:< http://www.arquivopublico.pr.gov.br/arquivos/File/pdf/rel_1887_p.pdf> Acessado em: $11 / 11 / 2017$.

RELATÓRIO do presidente da Província do Paraná Gomes Nogueira apresentado a Assembleia Legislativa em 15 de fevereiro de 1862. Disponível: <http://www.arquivopublico.pr.gov.br/arquivos/File/pdf/rel_1862_p.pdf > Acessado em: $11 / 11 / 2017$.

RELATÓRIO do presidente da Província do Paraná José Francisco Cardoso apresentado a Assembleia Legislativa em 01 de março de 1860. Disponível:< http://www.arquivopublico.pr.gov.br/arquivos/File/pdf/rel_1860_p.pdf> Acessado em: $11 / 11 / 2017$.

RELATÓRIO do presidente da Província do Paraná Polidor Cezar Burblamaque apresentado a Assembleia Legislativa em 15 de fevereiro de 1867. Disponível:< http://www.arquivopublico.pr.gov.br/arquivos/File/pdf/rel_1867_a_p.pdf> Acessado em: $11 / 11 / 2017$.

RIBEIRO, Darcy. O povo brasileiro: a formação e o sentido do Brasil. 2 ed. São Paulo: Companhia das Letras, 1995.

SILVA, Kalina Vanderlei; SILVA, Maciel Henrique. Dicionário de conceitos históricos. 2 ed. São Paulo: Contexto, 2009. 
SOUZA, Almir Antonio de. A Lei de Terras no Brasil Império e os índios do Planalto Meridional: a luta política e diplomática do Kaigang Vitorino Condá (1845-1870). In: Revista Brasileira de História, 2015. Vol. 35, $\mathrm{n}^{\circ}$ 70, p. 109-130. Disponível: <http://www.scielo.br/scielo.php?pid=S010201882015000200109\&script=sci_abstract\&tlng= pt>. Acessado em: 12/12/2017.

TAUNAY, V. de. Exposição com que o Sr. Dr. Alfredo Descragnolle Talnay passou ao administrador da Província do Paraná Exm ${ }^{\circ}$ Ser. Dr. Joaquim de Almeida Faria Sobrinho - ${ }^{o}$ Vice- presidente a 3 de maio de 1886. Disponível em: <http://www.arquivopublico.pr.gov.br/arquivos/File/pdf/exp1886_a_p.pdf>. Acesso em: 02/01/2018.

VALENCIA, José Francisco. Representações sociais e memória social: vicissitudes de um objeto em busca de uma teoria. Trad. Vanderley Jarbas Santos Clos. In: SÁ, Celso Pereira de. (Org.) Memória, imaginário e representações sociais. Rio de Janeiro: Museu da República, 2005.

\footnotetext{
i Anterior a Reforma Pombalina a educação indígena esteva submetida a ordem dos padres Jesuítas que controlavam os aldeamentos indígenas. Os jesuítas foram expulsos do país em 1757. Somente em 1843 foi permitida legalmente a entrada dos padres Capuchinhos para catequização indígena.

ii Delimitamos para este trabalho a análise do Diretório do Índios, cabe ressaltar que após essa fase, há as Cartas Régias de 1808 - uma delas específica ao que confere Curitiba e Guarapuava (espaço que a posteriori será o Paraná). Teve também os Apontamentos de José Bonifácio e, o principal do século XIX, que foi o Regulamento das Missões. Sobre a questão ver: OLIVEIRA (2018).

${ }^{\text {iv }}$ Sobre a Estrada da Mata ver: GOULARTI FILHO, Alcides. A Estrada da Mata e a integração regional pelo Brasil Meridional. In: Textos de Economia. Florianópolis, v.15, n.2, p.111-138, jul./dez.2012. Disponível:< https://periodicos.ufsc.br/index.php/economia/article/view/2175-8085.2012v15n2p111>. Acessado em: 12/12/2017.

${ }^{v}$ Nos documentos oficiais e na história oral em alguns momentos vamos encontrar a designação de bugres para os mesmos.

vi Sobre o episódio ver: MOTA, Lúcio Tadeu. Passo Ruim 1868: as estratégias dos Xokleng nas fronteiras de seus territórios do alto rio Itajaí. IN: Rev. Bras. Hist. [online]. 2017, vol.37, n.75, pp.169-193. Disponível em: <http://www.scielo.br/scielo.php?pid=S0102-01882017005004103\&script=sci_abstract\&tlng=pt $>$. Acessado em: $02 / 02 / 2018$

vii Uma braça equivale a 1,8288 metros. 50 braças equivalem a 91,44 metros.

viii No ano de 1896, aparecem os seguintes nomes da família Mattos qualificados como leitores no município de Rio Negro-PR: Francisco de Paula Mattos (52 anos); Higenio Silvério de Mattos (38 anos); José Antonio de Mattos (54 anos); José H. de Mattos (34 anos); Manoel Florencio de Mattos (28 anos); Pedro José de Mattos (32 anos); João Gonçalves de Mattos (46 anos) (LIVRO DE ATAS -1898 a 1903, p.34).

${ }^{\text {ix }}$ O relato da viagem de Alfredo d' Escragnolle Taunay foi publicado pelo filho em 1923, junto com outro relato de viagem para o Mato Grosso. O Visconde de Taunay assumiu o cargo de Presidente da Província do Paraná por cinco meses, de 29 de setembro de 1885 a 3 de maio do ano seguinte.
} 